\title{
Desenhando o mundo ideal e mundo real: um estudo sobre lésbicas, trabalho e inserção social
}

\author{
Drawing the ideal world and real world: a study of lesbian, labour and \\ social inclusion
}

http://dx.doi.org/10.5007/2178-4582.2014v48n2p303

\author{
Henrique Luiz Caproni Neto, Alexsandra Nascimento Silva \\ e Luiz Alex Silva Saraiva \\ Universidade Federal de Minas Gerais, Belo Horizonte/MG, Brasil
}

\begin{abstract}
No presente trabalho, buscamos analisar a experiência de mulheres lésbicas de Juiz de Fora, município de Minas Gerais, no âmbito do trabalho, da sociedade e do sujeito, a partir de desenhos por elas elaborados. Discutimos sobre a vivência da sexualidade e a lesbofobia como aspectos presentes em suas vidas e no trabalho, considerando que se inserem em um contexto heteronormativo. Realizamos uma pesquisa qualitativa com a elaboração de desenhos e entrevistas que possibilitaram a construção de categorias: ser lésbica, inclusão e inserção social, desenvolvimento pessoal e profissional, e mundo real e mundo ideal. Esses desenhos se mostraram como uma técnica rica e interessante para possibilitar o acesso a suas dimensões subjetivas e simbólicas relativas às suas vivências sociais e laborais. Por fim, defendemos uma postura reflexiva e crítica, tanto na sociedade como nas organizações, acerca dos padrões socialmente construídos e valorizados que podem marginalizar ou estigmatizar aqueles que fogem desses padrões
\end{abstract}

Palavras chave: Lésbicas - homofobia desenhos - organizações - inserção social
In this paper, we analyze the experience of lesbian women from Juiz de Fora, state of Minas Gerais, on the scope of their work, society and individual lives, based on drawings made by them. We discuss and consider the experience of sexuality and lesbophobia as aspects of their lives and work in an heteronormative context. A qualitative study was conducted from elaborations of drawings and interviews that allowed the construction of categories: being lesbian, inclusion and social integration, personal and professional development, and real world and the ideal world. The drawings showed to be a rich and interesting technique to provide access to their subjective and symbolic dimensions as well as to their social and work experiences. Finally, we advocate a reflective and critical posture both by the society and organizations on the socially constructed and valued patterns that can marginalize or stigmatize those who flee from them.

Keywords: Lesbians - homophobia drawings - organizations - social inclusion

\section{Introdução}

O tema da diversidade tem sido mais frequente nos estudos organizacionais brasileiros (FLEURY, 2000; ALVES; GALEÃO-SILVA, 2004; HANASHIRO; CARVALHO, 2005; SARAIVA; IRIGARAY, 2009; FLORES -PEREIRA; ECCEL, 2010), mostrando-se como uma temática academica e socialmente relevante. Com enfoque especificamente na diferença e na sexu- 
alidade, os trabalhos geralmente têm se dedicado, com primazia, ao estudo de homossexuais masculinos (SIQUEIRA et al., 2009; IRIGARAY; SARAIVA; CARRIERI, 2010; DINIZ et al., 2013; SOUZA; PEREIRA, 2013). Destarte, no contexto brasileiro, são escassas as pesquisas que tratam das experiências de mulheres lésbicas em relação ao trabalho havendo apenas especificamente o estudo de Irigaray e Freitas (2011). Assim, por meio de nossa pesquisa, buscamos contribuir também com essa problematização .

As homossexualidades têm sido reconhecidas como uma forma legítima de se vivenciar a sexualidade, ocupando espaço em diversos setores sociais, como na escola, nos jornais, nas revistas, na mídia, no cotidiano das pessoas, bem como nas organizações. Contudo, concomitantemente a essa maior visibilidade, as manifestações de preconceito e de discriminação ainda acontecem em variadas instâncias, como no mundo do trabalho, evidenciando a presença de dificuldades e modos de segregação. Dessa maneira, essa temática tem repercutido mais frequentemente na comunidade acadêmica brasileira em prol de igualdade de direitos, oportunidades e cidadania.

A homofobia, o estigma e o preconceito são aspectos a serem questionados especialmente no âmbito social tendo em vista que produzem experiências invisíveis e a negação de direitos sociais (PRADO; MACHADO, 2008; BORRILLO, 2010). Isso também se reflete nas organizações, posto que as relações de poder estabelecem, como norma, a heterossexualidade (SIQUEIRA; ZAULI-FELLOWS, 2006; LOURO, 2009).

Corroborando essa preocupação, o governo federal vem desenvolvendo um relatório sobre a homofobia no Brasil: as notificações de violência homofóbica revelaram que, no ano de 2012, houve 3.084 denúncias de homofobia (BRASIL, 2013) em diversas instâncias, mostrando que a cada dia 13,29 pessoas foram vítimas desse tipo de violência no Brasil ${ }^{1}$. O cotidiano de mulheres lésbicas é tomado por situações de violência e discriminação tanto no ambiente familiar, escolar, como naquele do trabalho e das organizações (LEONEL, 2011; IRIGARAY; FREITAS, 2011).

Nesse contexto, nosso trabalho tem como objetivo analisar a experiência de mulheres lésbicas de Juiz de Fora no âmbito do trabalho, da sociedade e do sujeito, a partir de desenhos por elas elaborados. Entendemos que os estudos sobre a diferença sexual e o trabalho são importantes já que o último se relaciona diretamente com a identidade e vida das pessoas influenciando em sua

1 Cabe considerar que é comum nesse tipo de pesquisa a subnotificação das violências e agressões em decorrência da cultura homofóbica e machista, ainda como nos casos das relações afetivas com o/a agressor(a) ou nos casos da falta de seriedade da autoridade policial em considerar tais agressões. Também deve-se apontar sobre a naturalização da violência e ou autoculpabilização, portanto: "cabe reiterar que as estatísticas analisadas ao longo dessa seção referem-se às violações reportadas, não correspondendo à totalidade das violências ocorridas cotidianamente contra LGBTs, infelizmente muito mais numerosas do que aquelas que chegam ao conhecimento do poder público" (BRASIL, 2013, p. 18). 
inserção social. Tais estudos também se mostram necessários para a reflexão sobre políticas públicas, bem como as organizacionais, para lidar com a problemática da homofobia e do preconceito.

Para atingir o objetivo proposto, discutimos sobre a vivência de ulheres lésbicas no trabalho, considerando aspectos como a lesbofobia, o preconceito e o estigma social, a assunção e a liberdade de experienciar a sexualidade no ambiente de trabalho e na sociedade. Este é um tema ainda pouco explorado na Administração, em âmbito nacional, especialmente no que se refere a mulheres lésbicas como sujeitos de pesquisa. Este estudo se configura como qualitativo tendo em vista a importância dos aspectos subjetivos e sociais nesse contexto. Para tanto, trabalhamos com desenhos como uma técnica projetiva não estruturada, e com entrevistas, por darem primazia a esses aspectos e por permitirem às participantes desenharem o que considerassem mais interessante e representativo de suas vidas; trata-se de uma técnica ainda não utilizada para se compreender a experiência dessas trabalhadoras no Brasil. A análise qualitativa dos dados possibilitou a construção de algumas categorias de análise: ser lésbica; o desenvolvimento pessoal e profissional; a inclusão e inserção social; e a dicotomia mundo real e mundo ideal. Por fim, trazemos algumas considerações tendo em vista a busca de uma visão crítica e não preconceituosa sobre as mulheres no contexto das organizações e do trabalho.

\section{Lesbofobia e violência no trabalho e nas organizações}

Diversas abordagens de debate cercam a temática das homossexualidades na sociedade, envolvendo aspectos jurídicos, de saúde, os movimentos sociais, o ambiente escolar, os meios de comunicação, o trabalho e as organizações. Apesar disso, a homofobia e, especificamente, a lesbofobia estão presentes nas trajetórias pessoais e profissionais das mulheres homossexuais e podem ser considerados meios para a afirmação e constituição da heterossexualidade compulsória ${ }^{2}$ (DINIS, 2011). A questão da homofobia ficou patente nos debates públicos e nas lutas sociais e políticas, principalmente a partir de meados do século XX (RIOS, 2007); além disso, tem se tornado necessário atentar para a especificidade das discriminações experimentadas por outros grupos como mulheres lésbicas.

A homofobia é um fenômeno complexo e variável que está presente em todos os segmentos sociais, podendo se manifestar de forma implícita, velada,

2 A heterossexualidade compulsória é a imposição de um modelo formado apenas pelas relações entre casais compostos por homens e mulheres, ou seja, um modelo de relações afetivas e sexuais somente entre pessoas do sexo oposto (MISKOLCI, 2012). Também, está associada com o gênero compreendido como norma que regulamenta as subjetividades e inteligibilidade definindo os parâmetros do que terá possibilidade de aparecer ou não no domínio do social, sendo um aparelho pelo qual o binário está instituído (BUTLER, 2004). 
e até mesmo com agressões físicas, diretas e explícitas, ou com manifestações de ódio. Essa terminologia é usualmente utilizada para denotar a atitude de hostilidade contra os/as homossexuais. Seria uma forma de mostrar o diferente como contrário, inferior ou anormal, estando longe do universo comum dos humanos, considerando a construção social de uma estigmatização aos homossexuais e às lésbicas (GOFFMAN, 1975; MOTT, 2000; BORRILLO, 2010; SARAIVA, 2012).

O tema costumava ser estudado apenas a partir de uma visão psicológica que demonstrou-se limitada, dado o componente social e institucional da homofobia e o heterossexismo ${ }^{3}$, entendendo que a discriminação atribui um significado negativo à diferença sexual (BORRILLO, 2010; RIOS, 2007). Em tal perspectiva, consideramos a homofobia um instrumental de dominação e poder que visa à heteronormatização ${ }^{4}$ de comportamentos sociais (ALMEIDA; SOARES, 2012), uma vez que, ao longo do tempo, a homossexualidade vem sido tratada negativamente seja como pecado, crime, ou patologia. Dessa forma, as lésbicas e os homossexuais são vítimas de discriminação e homofobia mesmo de modo não explícito, o que é fruto dessa visão negativa difundida em torno da sexualidade (FRAZÃO; ROSÁRIO, 2008; IRIGARAY; FREITAS, 2011). Logo,

\begin{abstract}
A homofobia passa a ser vista como fator de restrição de direitos de cidadania, como impeditivo à educação, à saúde, ao trabalho, à segurança, aos direitos humanos e, por isso, chegase a propor a criminalização da homofobia. Abrem-se aí novas frentes de batalhas, fogos cruzados, possibilidades e paradoxos políticos (JUNQUEIRA, 2007, p. 7).
\end{abstract}

No que tange ao trabalho e às organizações, a homofobia pode ser expressa em situações como aquelas em que o/a homossexual é excluído/a do processo seletivo em virtude da sua sexualidade. Assim, busca se "camuflar" de modo a não ser prejudicado/a no trabalho, devido à dificuldade de ascensão hierárquica, às diferenças de benefícios, ao tratamento desigual, à falta de efetividade nas políticas de respeito à diferença, às situações de assédio e violência (FERREIRA; SIQUEIRA, 2007; SIQUEIRA et. al., 2009; IRIGARAY; SARAIVA; CARRIERI, 2010; GARCIA; SOUZA, 2010; BICALHO et. al., 2011; IRIGARAY; FREITAS, 2011; SARAIVA, 2012; HEINTZ, 2012;

\footnotetext{
3 Heterossexismo se refere a pressuposição de que todos são ou deveriam ser heterossexuais (WELZER-LANG, 2000; MISKOLCl, 2012).

4 Como: "Qualquer comportamento que não se enquadre no padrão heteronormativo (relação binária homem/ mulher) e que fuja ao padrão machista e até mesmo misógino (entendendo que, numa hierarquia orientada pelo patriarcalismo, não há espaço para uma mulher emancipada e crítica) é tido como fora do padrão. Estar fora do padrão é descumprir, transgredir os papéis sociais que lhe são atribuídos socialmente e que, supostamente, deveriam ser entendidos como biologicamente determinados". (ALMEIDA; SOARES, 2012, p. 304 - 305).
} 
DINIZ et. al., 2013; CAPRONI NETO; SARAIVA; BICALHO, 2014). Além de reproduzirem práticas heteronormativas, as organizações e o mundo do trabalho devem ser problematizados como espaços permeados por relações de sexualidade e gênero envoltas pela dominação masculina e por um ideal heterossexista.

Ao refletirmos sobre mulheres lésbicas, já se pode evidenciar o conceito de lesbofobia, que são discriminações ou violências específicas experimentadas por elas em um determinado contexto social e histórico (BORRILLO, 2010) que enfatiza as assimetrias de gênero e mantém o tabu da orientação quanto à sexualidade (LEONEL, 2011). Destarte, no trabalho e nas organizações, a experiência de lésbicas não seria semelhante à de homossexuais masculinos, pela questão do sexismo que tem beneficiado os homens em detrimento das mulheres. E, ainda, seriam diferentes daquelas das mulheres heterossexuais, haja vista o heterossexismo que assume a heterossexualidade como uma norma hegemônica (HEINTZ, 2012).

Considerando o sexismo e o machismo, é importante salientar que o masculino foi construído historicamente como um lugar de poder, de ação, decisão, chefia, havendo uma naturalização disso na sociedade (MINAYO, 2005, p. 24): “[...] o masculino é investido significativamente com a posição social (naturalizada) de agente do poder da violência, havendo, historicamente, uma relação direta entre as concepções vigentes de masculinidade e o exercício do domínio de pessoas, das guerras e das conquista”. Isso também sucede no âmbito organizacional, uma vez que as empresas são construídas socialmente como espaços de dominação masculina nos quais as mulheres têm seu capital social sequestrado (REINHOLD, 2005; BOUDIEU, 2006); por exemplo, ainda são poucas as mulheres que alcançam altos cargos, como os de diretoria ou presidência (CARVALHO NETO; TANURE; ANDRADE, 2010). Ao refletirmos sobre mulheres lésbicas, podemos inferir que esse quadro de desigualdade e machismo é intensificado em função do preconceito e da heteronormatividade, como também apontado por Leonel (2011) e Irigaray e Freitas (2011).

Smigay (2002) salienta que os estudos que tratam de violência, quando não consideram o sistema de gênero, não são suficientes para lidar com a homofobia. Defende que:

apenas um pensamento antissexista é capaz de afirmar o direito a diferenças individuais, entre gêneros e intragêneros, descolados da biologia, rompendo com a perspectiva essencialista. Tal pensamento reconhece o peso da cultura e reconhece a alteridade como condição básica de respeito à pluralidade, ao multiculturalismo, às múltiplas expressões eróticas, sociais, sexuais (SMIGAY, 2002, p. 35). 
Para a autora, a violência faz parte da constituição do masculino, ressaltando que homens agem de acordo com padrões valorizados socialmente no mundo masculino, pois geralmente foram socializados para a misoginia, o sexismo e a homofobia. Desprezam os não viris e possuem condutas violentas, agindo conforme uma norma homofóbica e sexista. Dessa forma, a violência de gênero é uma violência que tem por característica o poder desigual entre os envolvidos, sendo os objetos privilegiados dessa violência: as mulheres, homens não viris, homens e mulheres homossexuais.

Na mesma direção, Welzer-Lang (2001), tratando da homofobia e da construção social do gênero masculino, destaca um paradigma de superioridade e dominação masculina perante às mulheres e que normativa a masculinidade para uma política homofóbica de gestão de corpos e desejos em que há estigmatização dos elementos socialmente associados ao feminino. Portanto, um quadro de dominação masculina e machismo, este entendido como:

[...] uma norma cultural que engloba todas as características
que são verdadeiramente masculinas. Muitos descreveram o
machismo em termos de indiferença a família, distanciamento
dos filhos, resistência à adversidades, assédio sexual, capacida-
de de beber muito, agressividade contra outros homens, domi-
nação em relação às mulheres (DESOUZA, BALDWIN, 2000,
p. 490).

Logo, pensar que lésbicas podem ter, hoje, mais facilidade para publicar a orientação sexual no trabalho que outrora pode não ser a realidade cotidiana, haja vista que várias situações de discriminação ainda predominam. Especificamente neste caso, verifica-se que, embora muitas vezes velado, o preconceito existe e influencia o comportamento delas dentro da organização, bem como o acesso (ou não) a cargos e benefícios. As homossexuais femininas, bem como os gays, se sentem discriminadas no mundo do trabalho e esta discriminação muitas vezes é dissimulada sob a forma do humor e de uma violência sutil ou simbólica (IRIGARAY; FREITAS, 2011; BICALHO et al., 2011; HEINTZ, 2012).

A orientação sexual é um traço significante que compõe a identidade dos sujeitos, que cria expectativas, estigmas e gera custos psicossociais. Os indivíduos homo, bissexuais e as lésbicas ainda são muitas vezes considerados como moralmente desviantes e essa crença leva ao seu desacreditamento social, o que compromete seu desempenho no ambiente de trabalho, onde enfrentam dificuldades. O estigma é algo socialmente construído e tem implicações negativas na vida dos que o sofrem. No caso dos/das homossexuais, o estigma independe do indivíduo assumir a sua orientação ou não, pois o que desen- 
cadeia o estigma é a percepção do outro. Por isto, muitos/as ocultam a sua orientação no ambiente de trabalho (GOFFMAN, 1975; PACHANKIS, 2007; SIQUEIRA et. al., 2009; IRIGARAY; FREITAS, 2011; HEINTZ, 2012).

Os estigmas podem ser compreendidos como marcas que demonstram algo de extraordinário ou negativo a respeito do status moral de quem as apresenta. Assim, nas relações sociais, determinado atributo, como a homossexualidade e a lesbianidade, pode torná-lo um outro pertencente a uma categoria má ou perigosa, indo de uma pessoa comum a uma estragada e menor. É uma relação pautada por símbolos que demonstram uma quebra de um retrato coerente que desvaloriza o indivíduo. Logo, as homossexualidades são vistas como um tipo específico de estigma relacionado com as culpas de caráter individual, de uma forma em que a lógica desse estigma se impõe na relação social, afastando, concomitantemente, os outros dessa relação e impossibilitando que dirijam sua atenção para outros atributos dos sujeitos, condenando-lhes à marginalidade e a um lugar periférico nas organizações (GOFFMAN, 1975; SARAIVA, 2012).

Desse modo, apesar de existir no ambiente organizacional um discurso de neutralidade em relação à heterogeneidade dos indivíduos que nele convivem (SARAIVA; IRIGARAY, 2009), as minorias, como as mulheres lésbicas, são alvo de discriminação e punição no interior desses espaços, o que implica ,o silenciamento das minorias nelas presentes, em prol do discurso dominante e heteronormativo. Tais práticas impedem que os homossexuais vivam suas afetividades de forma plena, bem como dificultam a entrada e ascensão deles no mundo corporativo (DUFFY, 2010; IRIGARAY; FREITAS, 2011).

O trabalho, como parte importante da vida das pessoas, representa um espaço em que ocorre o encontro com o outro, o que lhes confere um senso de identificação com a sociedade e de reconhecimento como membros da comunidade. Para a mulher lésbica, trabalho e identidade se sobrepõem proporcionando um sentido de realização. É por meio do trabalho que têm contato com a comunidade trabalhadora e a possibilidade de participarem da sociedade enquanto trabalhadoras, consumidoras e cidadãs. Ademais, o trabalho possibilita uma grande parte das experiências humanas, fornecendo o senso de si mesmas, valor e realização. Dessa forma, a decisão entre assumir a sua orientação sexual no trabalho ou não é algo importante, que pode envolver barreiras ou ser um fator facilitador, de acordo com a cultura organizacional (DUFFY, 2010; IRIGARAY; FREITAS, 2011; CAPRONI NETO; SARAIVA; BICALHO, 2014).

As lésbicas são alvo de discriminação em seus ambientes de trabalho. De uma forma geral, sua sexualidade adquire visibilidade de modo negativo, por 
meio de piadas, estereótipos e fofocas. Tais situações desagradáveis levam muitas a manterem oculta sua orientação sexual, como forma de proteção à lesbofobia. Ao saírem do "armário", ficam mais vulneráveis ao julgamento e a terem suas competências questionadas. Além disso, temem as consequências negativas que "sair do armário" pode acarretar como, por exemplo, serem preteridas em situações de promoção ou isoladas por aqueles que poderiam ajudá-las em suas carreiras (DUFFY, 2010; IRIGARAY; FREITAS, 2011; HEINTZ, 2012).

Destarte, em seus labores, têm que negociar suas identidades privadas e públicas, muitas vezes não comentando sobre suas vidas pessoais de modo a não explicitarem a sua lesbianidade, tendo em vista o preconceito social, a ausência de suporte social e compreensão quanto à sexualidade, acarretando a não revelação da própria sexualidade (DUFFY, 2010; IRIGARAY, FREITAS, 2009). A lesbofobia ainda tende a ser intensificada para com aquelas que possuem um comportamento masculinizado, menor poder aquisitivo, não possuem a pele de cor branca ou se distanciam de um ideal de estética socialmente valorizado (IRIGARAY; FREITAS, 2009).

\section{Metodologia}

Por se tratar de uma temática subjetiva, a presente pesquisa é qualitativa, tendo em vista que é importante compreender e apreciar a visão, a perspectiva e a realidade a partir desses sujeitos. Esta pesquisa é útil por abranger "uma compreensão profunda de certos fenômenos sociais apoiados no pressuposto da maior relevância do aspecto subjetivo face à configuração das estruturas societais" (HAGUETTE, 2003, p. 63).

Com o objetivo de abarcar a subjetividade e o mundo simbólicos das trabalhadoras lésbicas, indo além da dimensão das palavras, utilizamos a técnica de construção de desenhos que "visa estimular a manifestação de dimensões emocionais, psicológicas e políticas, pouco privilegiadas por técnicas de cunho racional. Existem diversos motivos para sua utilização. O motivo maior é ir além das palavras escritas ou do que os discursos orais podem revelar" (VERGARA, 2006, p. 173). Desse modo, em virtude da ambiguidade e subjetividade presentes nas técnicas projetivas e expressivas de elaboração de desenhos, ressalta-se que os sujeitos evidenciam características internas na construção de suas respostas (CARTER; DANIELS; ZICKAR, 2013). Há a possibilidade de o sujeito expressar, através deles, conteúdos simbólicos e de sua vivência emocional relacionados ao contexto social em que se inserem (REZENDE et al., 2009). 
Nesse sentido, as técnicas projetivas se destacam por terem os seguintes benefícios: versatilidade, ao serem combinadas com outras técnicas, principalmente por serem utilizadas no nível individual; envolvimento, pois causam curiosidade aos entrevistados, são não usuais e intrigantes em comparação com os questionários, por exemplo; tendem a ser divertidas após a surpresa inicial; e permitem geração de ideias, pela ambiguidade, o entrevistado pode considerar qualquer quadro de referência, permitindo, assim, que surjam diferentes pontos de vista (CASTERALL; IBBOTSON, 2000).

Utilizamos a construção de desenhos de forma não estruturada, permitindo que as lésbicas desenhassem o que consideravam mais interessante e representativo de suas vidas e modos de ser. Desse modo, solicitamos às entrevistadas que elaborassem três desenhos nas seguintes vertentes: como é ser lésbica; a representação do trabalho para si; e sua vida em sociedade. Após a realização de cada desenho, com o suporte de um gravador de voz, pediu-se a elas que explicassem o que desenharam, sobre o que refletiram e analisaram para desenvolver os desenhos.

As entrevistadas foram cinco mulheres lésbicas de Juiz de Fora, Minas Gerais, e sua participação na pesquisa ocorreu em julho de 2013. Foram selecionadas a partir de contatos pessoais dos pesquisadores e pela técnica de bola de neve (snowball) na qual uma entrevistada indica a outra. Essas entrevistas ocorreram em locais públicos da cidade como restaurantes, cafeterias ou em seus próprios locais de trabalho. Todas se mostraram dispostas a participar e permitiram a gravação das conversas sobre os desenhos. O quadro 1 sintetiza o perfil das entrevistadas.

\section{Quadro 1. Caracterização dos sujeitos de pesquisa}

\begin{tabular}{|c|c|c|c|c|c|c|}
\hline Código & Cor & Idade & $\begin{array}{c}\text { Tempo de } \\
\text { trabalho } \\
\text { (anos) }\end{array}$ & Formação & Cargo/Função & $\begin{array}{l}\text { Tipo de } \\
\text { empresa }\end{array}$ \\
\hline E1 & Branca & 34 & 18 & Economia & Empresária & Gráfica \\
\hline $\mathrm{E} 2$ & Branca & 27 & 10 & Artes & $\begin{array}{c}\text { Empresária/ } \\
\text { Chef de cozinha }\end{array}$ & $\begin{array}{l}\text { Alimen- } \\
\text { tícia }\end{array}$ \\
\hline E3 & Parda & 41 & 23 & Ensino médio & Gerente & Padaria \\
\hline E4 & Branca & 41 & 30 & $\begin{array}{l}\text { Ensino funda- } \\
\text { mental }\end{array}$ & $\begin{array}{l}\text { Ajudante de } \\
\text { cozinha }\end{array}$ & $\begin{array}{c}\text { Restau- } \\
\text { rante }\end{array}$ \\
\hline E5 & Branca & 30 & 7 & Fisioterapia & $\begin{array}{c}\text { Fisioterapeuta } \\
\text { autônoma }\end{array}$ & - \\
\hline
\end{tabular}

Fonte: quadro elaborado pelos autores 
Para a análise qualitativa dos desenhos e das entrevistas, os pesquisadores discutiram conjuntamente sobre as possíveis categorias, o que possibilitou chegar a quatro principais: ser lésbica, desenvolvimento pessoal e profissional, inclusão social e profissional, e mundo real e mundo ideal.

\section{Análise dos desenhos}

\section{Ser lésbica}

Esta primeira categoria busca compreender as representações e os sentidos nos modos de ser lésbica para essas mulheres trabalhadoras. No primeiro desenho abaixo, diversos aspectos relacionados com elementos associados culturalmente ao mundo feminino para falar de si se encontram expressos como a referência aos olhares, as curvas, a flor, ao coração, à música, ao violão, ao corpo feminino.

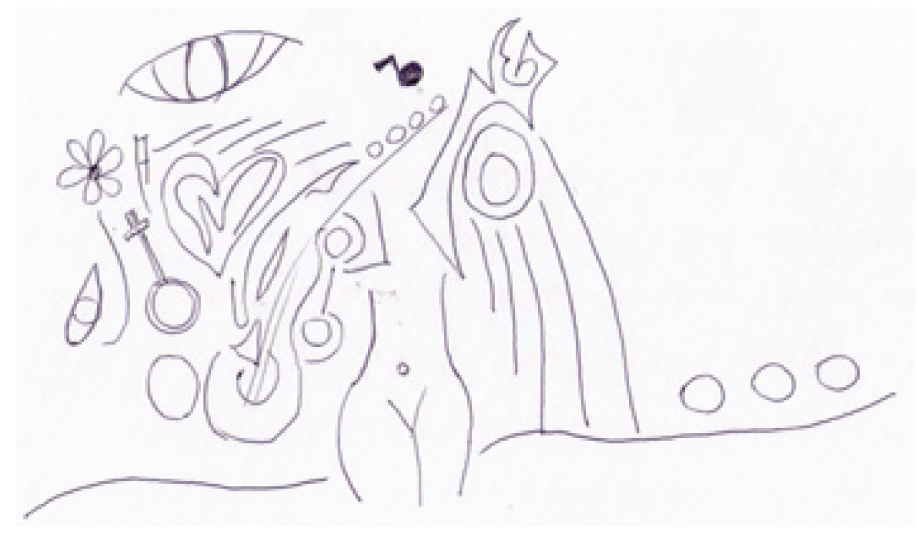

A participante reflete sobre seu desenho e o que buscou expressar nele:

Bem, eu enquanto lésbica, eu acredito na multiplicidade. Então, por exemplo, quem é gay, eu acredito nisso por enquanto, eu acredito que a visão que eu tenho do mundo, a multiplicidade de conceitos, a cabeça aberta, isso diz muito sobre mim. A facilidade de entender a pessoa que é diferente, de ter vivido uma experiência que não é comum pra sociedade, mas que você tem que dar um jeito de sobressair sobre isso. Entendeu? E ser você mesmo independente das outras pessoas, e aceitar. Eu acho que é isso, na verdade. De você ter a capacidade, pelo menos eu ter a capacidade, de ter uma visão além de algumas pessoas, de não ter um preconceito, apesar de que existem vários tipos de preconceito, mas de não ter um preconceito, como fala, um preconceito sobre essas coisas, sobre outras coisas, até por causa da minha formação. Eu acho que é isso: multiplicidade [...] São várias coisas, na verdade. A mulher é muito apaixonada, então, o coração. Tem o desenho de uma mulher, que é o feminino também, são varias 
linhas, porque são linhas de raciocínio e linhas de frequência, e são três pontos porque existe uma continuidade. Então, é um desenho que não se acaba, é um desenho que continua. Porque, a minha formação é esta, enquanto lésbica eu estou vivendo e me formando a cada dia. (Trecho de E2)

É interessante a percepção da entrevistada sobre si mesma, enquanto uma pessoa pautada pela multiplicidade por ser lésbica, no sentido de que, como membro de um grupo minoritário, teria maior abertura e facilidade para se relacionar com aqueles que são "diferentes". Nota-se também que ser lésbica associa-se, em um contexto social heteronormativo, com a busca de uma vivência autônoma e espontânea de sua sexualidade, buscando sobressair-se diante do preconceito social. Assim, tal multiplicidade também se reflete no que buscou expressar em seu desenho, inclusive demonstrando um ideal de feminilidade e de si em direção a aspectos românticos, que são culturalmente associados ao mundo feminino. Além disso, como expressão de si, o desenho, ao apontar reticências, não teria fim, pois ser uma mulher lésbica não é algo imutável envolvendo um processo contínuo de constituição e formação (TROIDEN, 1988).

No segundo desenho, a expressão de si como lésbica faz referência a quatro mulheres.

Essa trabalhadora fala sobre sua intenção com o desenho:

Eu hoje tenho a maturidade para não me ver diferente de ninguém, nem enquanto profissional e nem enquanto gay. Não tenho vergonha de ser gay. Não me sinto diferente por ser gay $[\ldots]$ as figuras parecidas. Foi o que eu tentei. Eram para serem iguais... (Trecho de E1).

Podemos inferir, pelo desenho e pela sua reflexão, que a participante buscou destacar uma mudança em sua postura em referência à sua sexualidade. Assim, em comparação com momentos passados, a vivência de ser lésbica estava associada à vergonha e ao medo pelo receio da desvalorização social e profissional, o que também ocorre entre homens gays (FERREIRA; SIQUEI- 
RA, 2007). Atualmente, demonstra a aceitação de sua sexualidade e, assim, ser lésbica é um aspecto incorporado à sua vida e identidade de tal forma que não se vê mais diferente ou desigual à qualquer pessoa em razão disso (TROIDEN, 1988; NUNAN, 2003).

\section{Desenvolvimento pessoal e profissional}

Nesta categoria, inserem-se os desenhos que remetem ao desenvolvimento pessoal e profissional vivenciado pelas participantes enquanto lésbicas. O próximo desenho aborda diretamente a vivência pessoal representada por um gráfico ascendente. Desse modo, o desenho elaborado pela participante apresenta uma curva ascendente, com uma ponta de seta em sua extremidade havendo, em continuação à curva, uma linha pontilhada. Abaixo da curva, mas ainda dentro dos eixos do gráfico, notam-se três figuras femininas que a representam, dispostas lado a lado, em ordem crescente:

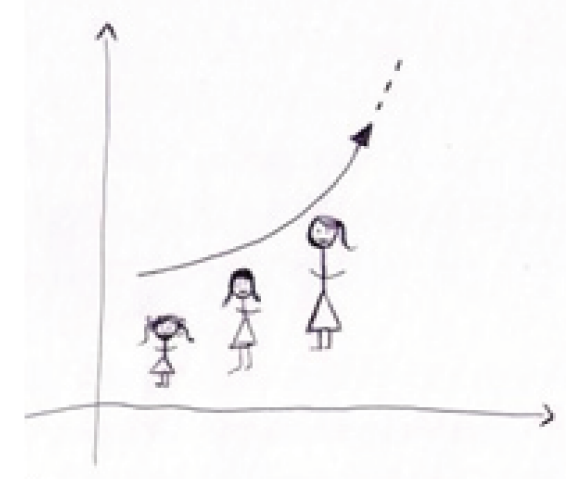

Eu associei alguma coisa com Administração. Então, eu fiz tipo um gráfico, já que o meu trabalho tem a ver. Aí, eu fiz uma curva tipo evoluindo assim, então, porque eu pensei assim: quando a gente começa a descobrir essa questão dentro da gente, é como se a gente fosse uma criança naquele mundo que se abre assim. E a gente nasce pra aquilo, e vai evoluindo. Psicologicamente, o modo de você se vestir, o modo de você lidar com as coisas e começar, de repente, a se mostrar pro mundo e pra você mesma se aceitar. E foi nesse sentido que eu coloquei crescendo. Acho que eu estou melhorando nesse sentido.

[E você pode me falar como foi isso na sua trajetória, o que você pensou?] 
Então, e eu ate coloquei aqui como continuar crescendo, porque assim, pra mim, pelo menos. Quando eu comecei a ver que eu tinha assim, um interesse em mulher, aquilo foi muito complicado, foi como se tivesse sido um choque mesmo, de certa. Porque eu tive uma criação toda certinha, com meus pais, aquela coisa da religião e tal. Então, eu acho que até eu ver que era isso mesmo, demorou um tempo. E aquilo foi com o tempo, as coisas foram ficando mais fáceis dentro de mim. Eu primeiro me aceitar, pra depois começar a querer que o outro também aceite. E ainda não. Muitas coisas pra mim ainda são difíceis. Eu nem chego pra todo mundo e falo, e também eu nem acho que precise falar. Mas, em algumas situações, acho que se eu falasse seriam mais fáceis pra mim. E eu ainda tenho essa dificuldade de falar. Só se a pessoa me perguntar, e mesmo assim eu ainda vou ficar toda sem graça. Ao contrário da (nome da companheira), por exemplo, até comparando com ela, que pra ela é muito mais fácil essa situação. Pra alguns amigos meus que eu vejo que é mais tranquilo, a (nome de uma amiga), já chega, já fala, já brinca. Pra mim isso ainda é bem complicado. Mas já melhorou muito, já evoluí muito. (Trecho de E5)

Ao mencionar seu desenvolvimento pessoal no que tange à sexualidade, a participante representa sua vivência pela metáfora de um gráfico, algo que está associado ao seu simbólico pois realizava graduação em Administração. Então, reflete sobre o desenvolvimento de si enquanto lésbica. Destarte, no início dessa vivência, refere-se a si como uma criança, ou seja, alguém que ainda tem muito a descobrir.. Logo, aborda o contexto familiar conservador em que foi socializada, e isso reflete uma dificuldade em sua trajetória, tal como observado por Teixeira et al. (2012) sobre as dificuldades dos jovens e adolescentes vivenciarem suas lesbianidades e homossexualidades. Focando um contexto mais recente, menciona sobre sua auto-aceitação e que esses aspectos têm melhorado em sua vida. Porém, há contradições como a dificuldade em abordar e falar claramente sobre isso, haja vista o contexto heteronormativo em que vive.

No tocante à temática do desenvolvimento, foi representada, adiante, uma paisagem: na dimensão superior, nota-se um céu, com nuvens e pássaros voando, e o sol à direita; na parte inferior, sobre o chão com vegetação rasteira, tratam-se de cinco árvores com frutos que possuem tamanhos diferentes $\mathrm{e}$ estão dispostas em ordem crescente.

Bom, nesse caso aqui, eu, é eu (sic) bem nova, ainda na infância, projetando, sem saber o que eu ia ser da vida. Então, essa segunda árvore aqui, eu já tô meio que quase na adolescência mesmo, sozinha, tudo da mesma cor. E aqui, nessa árvore segunda, eu percebi que eu gostava de mulher também. De primeiro eu não sabia, eu já gostava, mas não sabia que era isso realmente. Mas, na terceira árvore, eu já sabia o que eu queria 
da vida. (...). E, nesse quadro aqui, eu já estou trabalhando. (...) Aqui, eu já tô trabalhando, já tô trabalhando há muito tempo, já tô buscando uma vida estruturada com uma pessoa, já estou

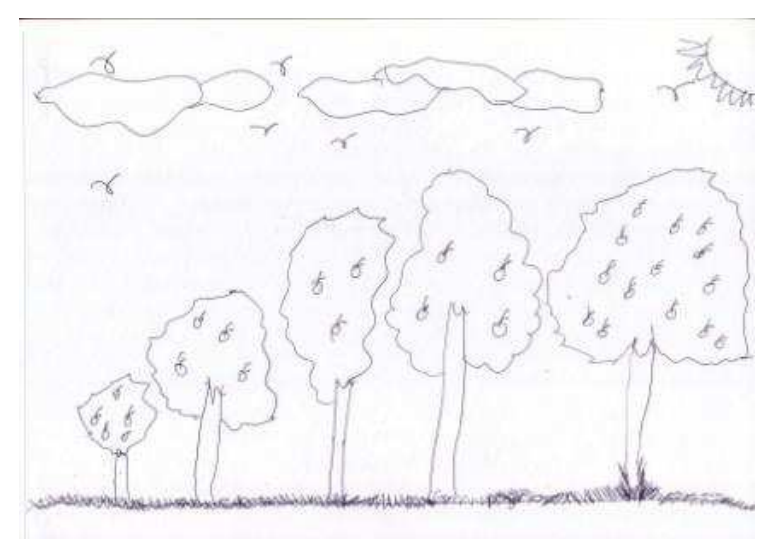

casada com uma companheira, no caso. E trabalhando, tendo meu apartamento. Aqui nessa terceira árvore, eu já estou estabelecida já. Casada há quase oito anos. (...). Minha casa fixa, meu apartamento comprado. Estou bem. Tanto no meu trabalho profissional, com tendência a crescer, eu na empresa. E eu estou bem, eu me sinto feliz. Lá sabem da minha opção, a maioria das pessoas sabe e me respeitam. Sou muito tranquila lá. Agem normalmente comigo e sabem que eu tenho uma companheira. Nessa ultima árvore aqui eu estou firme, eu estou bem (Trecho de E3).

Pode-se salientar que a sexualidade e o trabalho fazem parte do desenvolvimento dessa entrevistada enquanto sujeito na sociedade (HEINTZ, 2012). Destarte, reflete sobre sua vida e formação por meio da metáfora das árvores, indicando uma percepção positiva de si, representada pelas árvores com frutos e as conquistas em sua vida. Ressaltando a metáfora das árvores, a percepção de sua sexualidade ocorre cedo em sua trajetória, algo que ela relaciona com a segunda árvore. $\mathrm{O}$ trabalho aparece como algo importante, associado à terceira árvore, pensado como um projeto de vida aliado à união com sua companheira. Em seu desenvolvimento, trabalho e sexualidade se entrelaçam pela sua aceitação e das pessoas com as quais convive, vendo-se como uma árvore "firme" e "enraizada".

Essas reflexões tiveram como foco principal o aspecto individual; assim, faz-se necessário abordar a experiência social das entrevistadas, uma vez que esses âmbitos influenciam-se mutuamente. 
A presente categoria busca analisar as vivências e percepções de trabalhadoras lésbicas em grupos sociais. No primeiro desenho, evidencia-se uma clara demarcação sobre a inserção e inclusão social: a entrevistada se compreende dentro ou fora de determinados círculos que remetem aos grupos sociais.

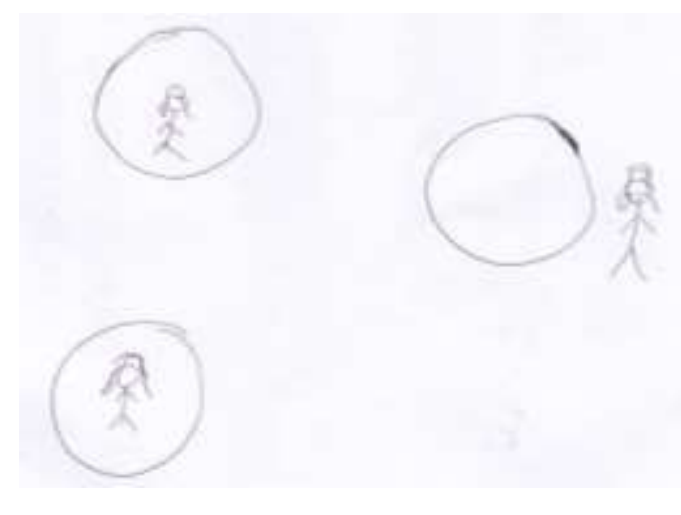

Trazemos, adiante, sua reflexão a partir de seu desenho:

Quando a gente pensa num convívio social, nos grupos sociais que a gente faz parte. Eu, como gay, em alguns grupos eu me enquadro, e em outros não dá, a gente não se enquadra. Convívio social religioso, a gente não se enquadra, a gente tá fora. Convívio social, de sair, de bares, de restaurantes, de frequentar, apesar da gente não... Eu, pelo menos, não ter vergonha nenhuma, mas a gente não vai se expor. Não vai ter a mesma postura que um casal hetero. Mas, se enquadra. $\mathrm{O}$ único grupo social que eu acho que a gente não se enquadra, é discriminado mesmo é na parte religiosa, direto e reto, não tem solução. [...] A igreja vem muito na minha cabeça como se fosse uma família muito católica. Então, na hora que eu ouço assim... Eu sei que, eu tenho discernimento pra saber que não é assim, mas mexe um pouco. A gente não se enquadra. (Trecho de E1)

Podemos analisar que a sexualidade aparece como demarcadora da posição da mulher lésbica em relação aos grupos sociais, ou seja, um aspecto relevante em suas vidas em sociedade. Em determinados grupos sociais, a entrevistada se percebe aceita, como em ambientes de bares e restaurantes. Nota-se também a postura de aceitação, enquanto consumidora, porém evidencia-se ainda o cuidado sobre a lesbianidade de tal forma a evitar a exposição e, talvez, algum possível ato discriminatório (GOMIDE, 2007). Nesse 
sentido, heteronormatividade é um fator que influencia o comportamento e o agir de mulheres lésbicas em várias esferas sociais (BORRILLO, 2010; DUFFY, 2010; HEINTZ, 2012). O desvio ao padrão hegemônico é demonstrado claramente quando analisa o papel da Igreja e a sua inserção social (BORRILLO, 2010).

Na mesma direção, o desenho seguinte compreende uma moldura, elaborado no sentido de representar a sociedade como um todo, englobando grupos sociais, sendo que a vida da participante nesses grupos está envolta por diversas interrogações e questionamentos.

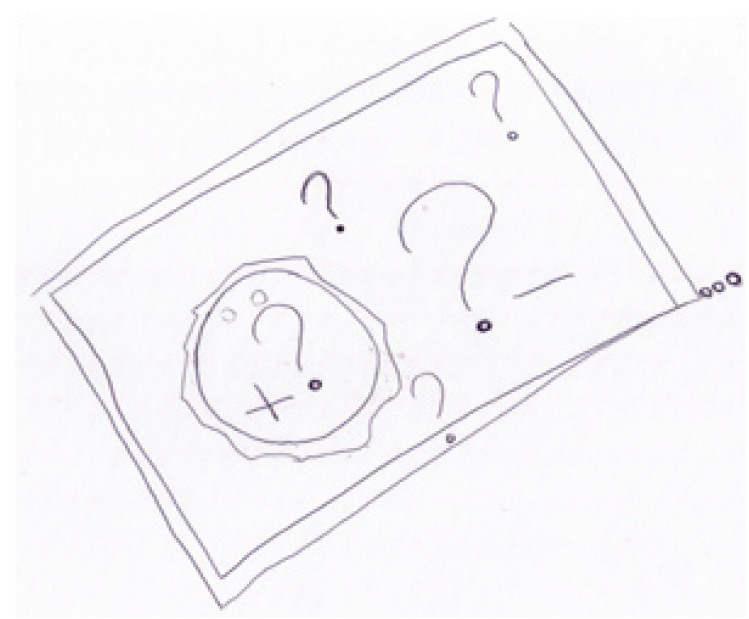

Suas reflexões em torno do desenhos e dessas questões abordam a complexidade e as incertezas sobre esse tema:

A sociedade é um círculo fechado, aonde você tem que acrescentar. Você tem que estar dentro dela pra acrescentar. Mas, até quando você acrescenta? $\mathrm{Na}$ verdade, isso faz surgir várias questões, mais questões do que respostas. Então, por exemplo, nós temos que estar dentro da sociedade pra poder somar. Nós não podemos estar fora. A partir do momento em que você trabalha você está incluído nisso tudo. Você está incluído nisto tudo. Eu como trabalhadora, eu como lésbica, eu como pessoa... $\mathrm{Na}$ verdade, surgem mais dúvidas do que certezas sobre o que isso significa. [...] $\mathrm{E}$ a sociedade é muito rígida em alguns pontos. Então, eu acho que isso gera dúvida. Entendeu? Em alguns momentos, você está inserida em alguns grupos, em alguns momentos você está fora desses grupos (Trecho de E2).

5 A heterornormatividade é a ordem sexual do presente que se impõe por violências físicas e simbólicas a aqueles que rompem as normas de gênero (MISKOLCI, 2012). Ainda, é entendida como empreendimento cultural e político tal como um processo social que vai sendo constantemente e continuadamente fabricado, produzido e tendo assim essa norma reiterada de uma forma muitas vezes sutil, buscando o alinhamento entre sexo, gênero e desejo em um ideal heterossexual (LOURO, 2009). 
Inicialmente, faz uma análise a respeito da importância da sua vida em sociedade para acrescentar algo, para somar, enquanto uma mulher lésbica trabalhadora. Em certo sentido, a sua inclusão adquire um caráter instrumental e contingencial tendo em vista que, como lésbica, há grupos para os quais é possível contribuir. Todavia, outros grupos sociais são rígidos quanto à sexualidade, evidenciando a dúvida e a aceitação de sua sexualidade em tais grupos e situações. Portanto, interrogações e dúvidas aparecem como metáforas para se pensar a real aceitação e inclusão de lésbicas na sociedade e nas organizações (SIQUEIRA et al., 2009; DUFFY, 2010; BICALHO et al., 2011; IRIGARAY; FREITAS, 2011).

\section{Mundo Real e Mundo Ideal}

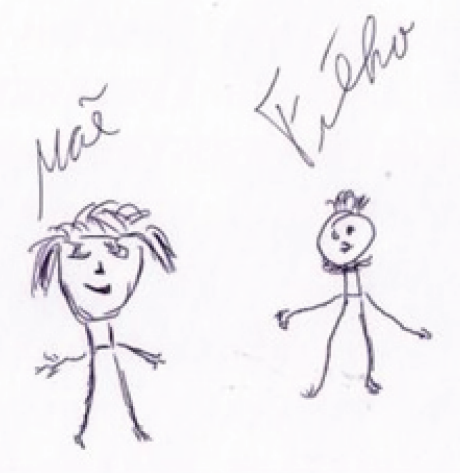

Na presente categoria, busca-se destacar a oposição mundo real e mundo ideal expressa em seus desenhos e representações de mundo. O mundo real, que representam por meio de desenhos, salientam as dificuldades experimentadas em relação à sexualidade, principalmente como a não aceitação familiar, bem como o preconceito e a discriminação no meio social. O seguinte desenho apresenta duas figuras humanas em referência às relações familiares: à esquerda, há uma figura feminina retratando a si pelos cabelos longos e pela inscrição "mãe" situada sobre o desenho; à direta, uma figura masculina com a palavra "filho". Ao ser indagada sobre o sentido do seu desenho, a entrevistada conta:

Ah, eu pensei nisso porque a minha família não aceita, né? Minha mãe me critica, me abomina, me joga pra lá. Fala que eu não sou filha dela, que não me quer em casa, que eu sou diferente da minha irmã, do meu irmão. Fala que não colocou filha no 
mundo pra ser sapatão. O meu filho é a mesma coisa, também não aceita não: "Ah, mãe, vai arrumar um homem pra você. Por que você tem que ficar com mulher?" (Trecho de E4)

O desenho foi produzido em resposta à solicitação de representar sua vida em sociedade. Pode-se salientar a importância da família em sua vida e interpretar que o convívio social é, para esta mulher, marcado pela intolerância que se manifesta em seu próprio seio familiar. As agressões são explícitas e envolvem um componente heternormativo mostrando um mundo que envolve preconceito e lesbofobia (GOMIDE, 2007; LEONEL, 2011).

Já o próximo desenho está em um caminho intermediário entre o mundo real e o mundo ideal, como analisaremos adiante:

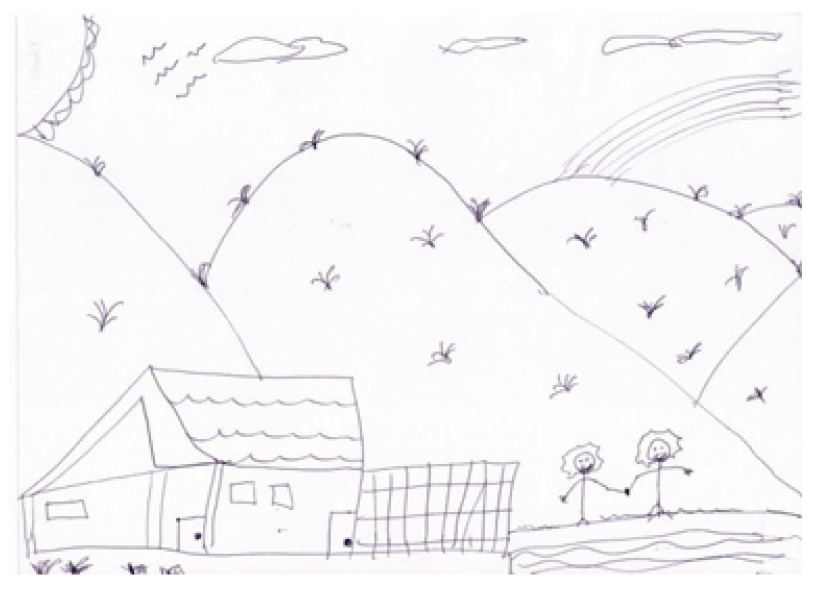

Nesse desenho aqui, que já é o final, que eu já tô bem estruturada, no trabalho, tanto no pessoal quanto no profissional. Então, eu tô aqui na nossa casa, a nossa casa na verdade, é meio que no campo, assim, e na frente tem o rio. Tem o riozinho, aonde eu gostaria mesmo que ficasse a casa, assim. Tô junto com a minha companheira, a gente tá de mãos dadas, a gente tá feliz assim. Aqui representa o arco-íris. E aqui é a natureza, uma coisa que eu gosto também. A nossa casinha, a gente feliz, do jeito que eu queria, o rio, o muro protegendo a casa, e a gente bem. Um dia bonito também.

[Você pensou em alguma coisa em relação à sociedade? Você desenhou um arco-íris...]

Então, esse desenho representa a liberdade, porque a gente tá feliz. Se a gente quiser andar na rua de mãos dadas, a gente pode. Não que eu vá fazer isso, mas a gente pode. Hoje em dia 
as pessoas estranham, falam "nossa, o que é isso?". E lá, se eu quiser andar de mãos dadas, eu vou andar tranquila. Ir num restaurante, e poder pegar na mão, sem aquele medo, de que o povo vai te olhar. Então, o arco-íris representa essa liberdade, perante a sociedade. Olha, o bonequinho está feliz.

[E hoje você acha que essa liberdade já foi atingida? Como que você vê isso?]

Já, eu acho. Já tá tranquilo, acho que mais do que isso pra mim, não precisa. Pra mim, como eu te falei. Eu tô bem, todo mundo me respeita. (Trecho de E3).

O desenho e a análise dessa participante mostra um mundo bonito - expressado por uma casa no campo envolta por rios, montanhas, arco-íris - enfatizando uma vida que faz referência à liberdade de comportamento, considerando uma casa e sua relação afetiva com sua companheira de um modo pleno e espontâneo. Porém de forma sutil, o desenho ainda expressa os obstáculos que articulam a vivência dessas mulheres que é visibilizada, por exemplo, na referência ao muro que protege a casa de seus sonhos e de seu mundo. No mundo ideal, elas podem andar de mãos dadas; contudo, no mundo real as pessoas "estranham", as encaram de um modo diferente. Apesar do ideal de liberdade, o medo e o receio perpassam o cotidiano dessas trabalhadoras (LEONEL, 2011).

O seguinte desenho também traz essa perspectiva de um mundo ideal pela liberdade quanto à expressão afetiva e sexual:

Eu desenhei aqui uma casa, pra mim, e ela mora junto. Entendeu? Por isso que eu desenhei isso. Uma casa pra eu e ela. É o que eu queria. Uma casa. Porque ela tem dois filhos, e o outro não aceita. Então, eu queria uma casa pra morar com ela longe daqui. Eu pensei nisso.

[Eu vi que você fez um sol.]

Eu fiz um sol, porque sempre que eu olho pro céu eu vejo o sol e lembro dela brilhando pra mim. 


\section{[E esse cachorrinho?]}

Esse cachorrinho é o cachorrinho que eu queria ter também, na minha casa. Eu fico pensando em mim e nela.

[E há quanto tempo vocês estão juntas?]

Há onze anos e três meses.

[E vocês duas morariam nessa casa. Por que você desenhou uma casa pra vocês morarem?]

Porque eu não tenho privacidade na minha casa. Entendeu?

\section{[Por que você não tem privacidade?]}

Porque eu tenho dois filhos que não aceitam esse tipo de coisa. eles não aceitam eu e ela. A gente mora sufocada dentro de uma casa, nós quatro.

[Essa casa seria então um local pra vocês ficarem mais tranquilas?]

Mais tranquilas. O sol pra ficar brilhando, que é ela, e o nosso cachorrinho.

[Tem mais alguma coisa que você queria falar sobre isso, alguma coisa que você ache interessante?]

Ah! Isso foi a melhor coisa que aconteceu na minha vida, conhecer ela. Hoje eu sou casada, tenho meus filhos, meu ex-marido não aceita também. Mas, eu passo por cima de tudo pra ficar com ela. Eu não me importa a opinião das pessoas, o que importa é eu. (Trecho de E4)

Tendo em vista o contexto familiar heteronormativo em que essa participante vive, ela conta que seu mundo ideal seria aquele em que pudesse vivenciar seu relacionamento com sua companheira de modo livre e sem restrições. O preconceito expresso na sociedade é tornado explícito pelos membros de sua família, como filhos e a mãe. Então, em seu mundo ideal, evidencia-se uma percepção romântica de seu relacionamento em referência ao sol, ao animal de estimação e à companheira. Mas, de forma, não tão explícita, esse mundo ideal é aquele em que há liberdade para sua vivência, bem como a educação e reflexão das pessoas quanto ao preconceito. 


\section{Algumas considerações}

Neste artigo, tivemos como objetivo analisar a experiência de mulheres lésbicas de Juiz de Fora no âmbito do trabalho, do indivíduo e da sociedade, a partir de desenhos por elas elaborados. Discutimos sobre a vivência da sexualidade e a lesbofobia como aspectos presentes em suas vidas e no trabalho. Então, realizamos uma pesquisa qualitativa com a elaboração de desenhos e com o auxílio de entrevistas a respeito dos mesmos, o que possibilitou a construção de categorias de análise: ser lésbica, inclusão e inserção social, desenvolvimento pessoal e profissional, e mundo real e mundo ideal

De um modo geral, a categoria de ser lésbica destaca desenhos relacionados com uma construção social e cultural do mundo feminino - abrangendo olhares, curvas, a flor, o coração, a música, o violão, o corpo feminino, a paixão e o amor por outra mulher -; também a lésbica pautada pela multiplicidade no sentido de que, como membro de um grupo minoritário, teria maior abertura e facilidade para se relacionar com aqueles que são "diferentes". Outra questão também evidencia o ser lésbica como ser igual a qualquer pessoa, não sendo diferente ou inferior no trabalho e na sociedade, assim demonstrando a naturalização e plena aceitação da sexualidade e de seus modos de ser.

Sobre o desenvolvimento pessoal e profissional, as entrevistadas buscam representar por meio de desenhos e metáforas, como uma árvore que está crescendo ou um gráfico ascendente, retratando sua descoberta e desenvolvimento quanto à sexualidade, às suas carreiras e trabalho, bem como suas expectativas quanto ao futuro.

A categoria de inclusão e inserção social trata de reflexões das entrevistadas no sentido que de que a sexualidade, expressa por meio dos desenhos, aparece como demarcadora de suas posições em relação a diversos grupos sociais. Destarte, em determinados grupos, elas seriam aceitas, por exemplo, como trabalhadoras ou consumidoras por terem a possibilidade de agregar ou contribuir. Todavia, em grupos sociais rígidos e com pouca abertura à diferença sexual, notam-se as dúvidas ou as interrogações quanto à sua real aceitação. Logo, cabe refletir que tipo de "aceitação" seria essa que se baseia em uma perspectiva instrumental tendo em vista a geração de valor como trabalhadoras ou consumidoras? Estariam próximas de uma real aceitação social e organizacional?

Na categoria de mundo real e ideal, enfatizam-se duas visões opostas. No tema do mundo real, salientam-se as dificuldades vivenciadas em relação à sexualidade, principalmente como a não aceitação familiar, bem como o preconceito e a discriminação no meio social. Já na temática do mundo ideal, 
destacam-se os sonhos e projetos quanto ao futuro; dessa maneira, os desenhos, como a construção de um lar, remetem à vivência da sexualidade e de seus relacionamentos de uma forma plena e espontânea. O que também está diretamente relacionado com a busca de uma sociedade e de organizações em que haja reflexão e não haja preconceito ou discriminação.

Os desenhos evidenciam a multiplicidade de aspectos em ser lésbica, bem como a aceitação desses aspectos pelas entrevistadas, sendo interessante compreender seu desenvolvimento pessoal e profissional por meio de metáforas. Também destacam a dificuldade dessas trabalhadoras quanto à sua real inserção e inclusão nos diversos grupos sociais. Assim, é preocupante notar que podem ser aceitas como trabalhadoras ou consumidoras, mas não simplesmente como mulheres lésbicas que buscam vivenciar sua sexualidade de forma plena e espontânea. Por fim, os desenhos da categoria de mundo real e mundo ideal reforçam ainda a distância entre uma sociedade que permite a livre expressão e vivência dos diferentes e aquela que pontua o que é considerado "desvio" e "normalidade".

É interessante ressaltar também que o presente trabalho, por se basear em uma técnica ainda não utilizada para se estudar trabalhadoras como mulheres lésbicas - a de construção de desenhos aliada a suas reflexões e análises quanto às entrevistas abertas sobre os mesmos - se mostrou como uma possibilidade interessante para se acessar suas dimensões subjetivas e simbólicas, tratando de suas vivências em sociedade e no trabalho e permitindo que expressassem o que consideravam mais representativo e relevante de suas experiências.

Não menos importante, defendemos uma postura reflexiva e crítica tanto na sociedade como nas organizações acerca dos padrões socialmente construídos e valorizados que podem marginalizar ou estigmatizar aqueles que fogem desses mesmos padrões. Logo, deve-se estar atento a esses padrões em busca de igualdade, da real aceitação e da não violência perante os não heterossexuais, especialmente as mulheres lésbicas, no mundo das organizações e do trabalho. Cabe também aos gestores e profissionais considerar esses aspectos para proporcionar um ambiente com qualidade de vida e sem segregação na organizações.

\section{Referências}

ALMEIDA, Marco Bettine; SOARES, Alessandro da Silva. O futebol no banco dos réus: o caso da homofobia. Movimento, Porto Alegre, v. 18, n. 01, p. 301-321, jan./mar. 2012.

ALVES, Mário Aquino.; GALEÃO-SILVA, Luis Guilherme. A crítica da gestão da diversidade nas organizações. Revista de Administração de Empresas, São Paulo, v. 44, n.3, p. 20-29, 2004. 
BICALHO, Renata de Almeida; DINIZ, Ana Paula Rodrigues.; CARRIERI, Alexandre de Pádua; SOUZA, Mariana Mayumi Pereira de. Symbolic violence and homosexuality: a study in Brazilian major cities. Far East Journal of Psychology and Business, Berkeley, v. 5, n. 1, p.1-22, 2011.

BORILLO, Daniel. Homofobia - história e crítica de um preconceito. Belo Horizonte: Autêntica, 2010. $144 \mathrm{p}$.

BRASIL. Relatório sobre a violência homofóbica no Brasil: ano de 2012, 2013. Disponível em: <http://www.sdh.gov.br/assuntos/lgbt/pdf/relatorio-violencia-homofobica-ano-2012> Acesso em: 19 dez. 2013

BUTLER, Judith. Undoing Gender. Routledge: New York, 2004. 288 p.

BOURDIEU, Pierre. A dominação masculina. 5a. ed. Rio de Janeiro: Bertrand Brasil, 2007, $160 \mathrm{p}$.

CAPRONI NETO, Henrique Luiz; SARAIVA, Luiz Alex Silva; BICALHO Renata de Almeida. Diversidade sexual nas organizações: um estudo sobre coming out. Revista Pensamento Contemporâneo em Administração, Rio de Janeiro, v. 8, n. 1, p. 86 - 103, 2014.

CARVALHO NETO, Antonio Moreira; TANURE, Betania; ANDRADE, Juliana. Executivas: carreira, maternidade, amores e preconceitos. Revista de Administração de Empresas, São Paulo, v. 9, n. 1, p. 1-17, jan. /jun. 2010.

CARTER, Nathan; DANIELS, Michael; ZICKAR, Michael. Projective testing: Historical foundations and uses for human resources management. Human Resource Management Review, New York, v. 23, p. 205-218, 2013.

CASTERALL, Miriam; IBBOTSON, Patrick. Using projective techniques in education research. British Educational Research Journal, London, v. 26, n. 2, p. 245-256, 2000

DINIS, Nilson Fernandes. Homofobia e educação: quando a omissão também é signo de violência. Educar em Revista, Curitiba, n. 39, p. 39-50, abr. 2011.

DESOUZA, Eros.; BALDWIN, John. A construção social dos papéis sexuais femininos. Psicologia: reflexão e crítica, Porto Alegre, v. 13, n. 3, p. 485 - 496, 2000.

DINIZ, Ana Paula Rodrigues.; CARRIERI, Alexandre de Pádua.; GANDRA, Gisele; BICALHO, Renata de Almeida. Políticas de diversidade nas organizações: as relações de trabalho comentadas por trabalhadores gays. Revista Economia e Gestão, Belo Horizonte, v. 13. n. 31 , p. $93-114,2013$.

DUFFY, Mell. Diversity in the Irish Workplace - lesbian women's experience as nurses. The International Journal of Diversity in Organizations, Communities and Nations. Champaign, v. 10, n. 3 , p. $231-241,2010$.

FERREIRA, Renata Costa.; SIQUEIRA, Marcus Vinícius Soares. O gay no ambiente de trabalho: análise dos efeitos de ser gay nas organizações contemporâneas. In: ENCONTRO ANUAL DA ASSOCIAÇÃO NACIONAL DE PỎS GRADUAÇÃO E PESQUISA EM ADMINISTRAÇÃO, XXXI, 2007, Rio de Janeiro. Anais... Rio de Janeiro: ANPAD, 2007. 
FLEURY, Maria Teresa Leme. Gerenciando a diversidade cultural: experiência de empresas brasileiras. Revista de Administração de Empresas, São Paulo, v. 40, n. 3, p. 18 - 25, 2000.

FLORES-PEREIRA, Maria Teresa.; ECCEL, Cláudia Sirangelo. Diversidade nas organizações: uma introdução ao tema. In. BITENCOURT, Cláudia. et al. . Gestão contemporânea de pessoas: novas práticas, conceitos tradicionais. Porto Alegre: Editora Bookman, 2010. 335 - 351 p.

FRAZÃO, Pedro; ROSÁRIO, Renata. O coming out de gays e lésbicas e as relações familiares. Análise Psicológica, Lisboa, vol. 1, n. XXVI, p. 25-45, 2008.

GARCIA, Antonio.; SOUZA, Eloisio Moulin de. Sexualidade e trabalho: estudo sobre a discriminação de homossexuais masculinos no setor bancário. Revista de Administração Pública, Rio de Janeiro, v. 44, n. 6, p. 1353-1377, nov./dez. 2010.

GOFFMAN, Erving. Estigma: notas sobre a manipulação da identidade deteriorada. Rio de Janeiro: Zahar, 1975. 124 p.

GOMIDE, Silvia. Formação da identidade lésbica: do silêncio ao queer. In: GROSSI, Miriam; UZIEL, Ana Paula.; MELLO, Luis (Org.). Conjugalidades, parentalidades e identidades lésbicas, gays e travestis. Rio de Janeiro: Garamond, 2007. 405 - 422 p.

HAGUETTE, Teresa Maria Frota. Metodologias qualitativas na sociologia. Petrópolis: Vozes, 2003.

HANSHIRO, Darcy Mitiko Mori; CARVALHO, Sueli Galego de. Diversidade Cultural: panorama atual e reflexões para a realidade Brasileira. Read, Porto Alegre, v. 11, n. 5, p. 1 -21, 2005.

HEINTZ, Phyllis. Work-life dilemmas emerging from lesbian executives narratives. The Career Development Quaterly, v. 60, n. 2, p. 122-133, June 2012.

IRIGARAY, Hélio Arthur Reis.; FREITAS, Maria Ester de. Sexualidade e organizações: estudo sobre lésbicas no ambiente de trabalho. Organizações \& Sociedade, Salvador, v. 18, n. 59, p. 625-641, out./dez. 2011.

IRIGARAY. Hélio Arthur Reis; SARAIVA, Luis Alex Silva; CARRIERI, Alexandre de Pádua. Humor e discriminação por orientação sexual no trabalho. Revista de Administração Contemporânea, Curitiba, v. 14, n. 5, p. 890-906. set./out. 2010.

JUNQUEIRA, Rogério Diniz. Homofobia: limites e possibilidades de um conceito em meio a disputas. Bagoas - estudos gays: gêneros e sexualidades, Natal, v. 1, n.1, p. 1-22, 2007.

LEONEL, Vange. Lesbofobia. In: VENTURI, Gustavo; BOKANY, Vilma. Diversidade sexual e homofobia no Brasil. São Paulo: Editora Fundação Perseu Abramo, 2011. 89 - 96 p.

LOURO, Guacira Lopes. Heteronormatividade e Homofobia. In: JUNQUEIRA, Rogério Diniz. Diversidade sexual na educação: problematizações sobre a homofobia nas escolas. Brasília: Ministério da Educação, Secretaria de Educação Continuada, Alfabetização e Diversidade, UNESCO, 2009.

MINAYO, Maria Cecília de Souza. Laços perigosos entre machismo e violência. Ciência \& Saúde Coletiva, Rio de Janeiro, v. 10, n. 1, p. 18 - 34, 2005. 
MISKOLCI, Richard. Teoria queer: um aprendizado pelas diferenças. Autêntica: Belo Horizonte, 2012. 78 p.

MOTT, Luiz. Causa Mortis: Homofobia - violação de direitos humanos e assassinatos de homossexuais no Brasil, 2000. Salvador: Editora GGB, 2000.

NUNAN, Adriana. Homossexualidade: do preconceito aos padrões de consumo. Rio de Janeiro: Caravansarai, 2003. 360 p.

PACHANKIS, John. The psychological implications of concealing a stigma: A cognitive-affective-behavioral model. Psychological Bulletin, v. 133, n.2, p. 328-345, 2007.

PRADO, Marco Aurélio Máximo; MACHADO, Frederico Vianna Preconceito contra homossexualidades: a hierarquia da invisibilidade. São Paulo: Editora Cortez, 2008. 143 p.

REINHOLD, Barbara. Smashing glass ceilings: why women still find it tough to advance to the executive suite. Journal of Organizational Excellence, v. 24, n. 3, p. 43-55, 2005.

REZENDE, Adryene Milanez; BRITO, Valéria Fernandes Dias Silva; MALTA, Júlia Dias Santana; SCHALL, Virgínia Torres.; MODENA, Celina Maria. Vivências de crianças e adolescentes com câncer: o desenho fala. Iniciação Científica, Cesumar, Maringá, v. 11, n. 1, p. 73 - 82, jan./jun., 2009.

RIOS, Roger Raup. O conceito de homofobia na perspectiva dos direitos humanos e no contexto dos estudos sobre preconceito e discriminação. In: POCAHY, Fernando. Rompendo o silêncio: homofobia e heterossexismo na sociedade contemporânea. Políticas, teoria e atuação. Porto Alegre: Nuances, 2007

SARAIVA, Luis Alex Silva; IRIGARAY, Hélio Arthur Reis. Políticas de diversidade nas organizações: uma questão de discurso? Revista de Administração de Empresas, São Paulo, v. 49, n. 3, p. 337-348, Jul./Set., 2009

SARAIVA, Luis Alex Silva. Além dos estigmas profissionais. In: FREITAS, Maria Ester de; DANTAS, Marcelo. Diversidade sexual e trabalho. São Paulo: Cengage learning, 2012.

SIQUEIRA, Marcus Vinícius Soares; SARAIVA, Luis Alex Silva; CARRIERI, Alexandre de Pádua; LIMA, Helena Karla Barbosa de; ANDRADE, Augusto José de Abreu. Homofobia e violência moral no trabalho no Distrito Federal. Organizações \& Sociedade, Salvador, v. 16, n.50, p. 447-461, jul./set. 2009.

SMIGAY, Karin Ellen Von. Sexismo, homofobia e outras expressões correlatas de violência: desafios para a psicologia política. Psicologia em Revista, Belo Horizonte, v. 8, n. 11, p. 32 46, jun. 2002.

SOUZA, Eloisio Moulin; PEREIRA, Severino Joaquim Nunes. (Re)Produção de heterossexismo e heteronormatividade nas relações de trabalho: a discriminação de homossexuais por homossexuais. Revista de Administração Mackenzie, São Paulo, v. 14, n.4, p. 76 - 105, 2013.

TEIXEIRA, Fernando Silva; MARETTO, Carina Alexandre Rondini; SANTOS, Élcio Nogueira dos ; MENDES, Andressa Benini. Homofobia e sexualidades em adolescentes. Psicologia: ciência e profissão, Brasília, v. 32, n. 1, p. 16-33, jan./mar. 2012. 
TROIDEN, Richard. Homosexual identity development. Journal of Adolescent Health Care, Oxford, v. 9 n. 2, p. 105-113, Mar., 1988.

VERGARA, Sylvia Constant. A utilização da construção de desenhos como técnica de coleta de dados. In: VIEIRIA, Marcelo Milano Falcão; ZOUAIN, Déborah Moraes. Pesquisa qualitativa em Administração, Rio de Janeiro: FGV, 2006.

WELZER-LANG, Daniel. A construção do masculino: dominação das mulheres e homofobia. Revista de Estudos Feministas, Florianópolis, v. 9, n. 2, p 460-481, 2001.

Submissão em: 06/09/2014

Aceite em: 01/12/2014

Henrique Luiz Caproni Neto é graduado em Administração e especialista em Gestão de Pessoas, ambos pela UFJF, mestrando em Administração - Estudos Organizacionais e Sociedade pela UFMG. Participa do Núcleo de Estudos Organizacionais \& Sociedade do CEPEAD/FACE/UFMG. Endereço para correspondência: NEOS - Núcleo de Estudos Organizacionais e Sociedade. Campus UFMG. Av. Antônio Carlos, 6627. Faculdade de Ciências Econômicas/FACE. Salas 4070/4071/4072. Pampulha. Belo Horizonte/ MG, Brasil. CEP:31270-901 E-mail: henriquecap_adm@yahoo.com.br

Alexsandra Nascimento Silva é graduada em Administração pela Universidade Federal de Minas Gerais.

E-mail: alexsandra.nsilva@gmail.com

Luiz Alex Silva Saraiva é professor Adjunto do Dep. de Ciências Administrativas da Faculdade de Ciências Econômicas da UFMG. Docente do Centro de PósGraduação e Pesquisas em Administração da FACE, e do Programa de PósGraduação Interdisciplinar em Estudos do Lazer da EEFFTO, ambos da UFMG. Doutor em Administração pela UFMG. Líder 2 do Núcleo de Estudos Organizacionais \& Sociedade. E-mail: saraiva@face.ufmg.br 